\title{
Prediction of laser drilled hole geometries from linear cutting operation by way of artificial neural networks
}

\author{
Gabriele Baiocco $^{1}$. Silvio Genna ${ }^{1,2,3} \cdot$ Claudio Leone $^{2,3} \cdot$ Nadia Ucciardello $^{1,2,3}$
}

Received: 26 October 2020 / Accepted: 1 March 2021 / Published online: 1 April 2021

(C) The Author(s) 2021

\begin{abstract}
This paper deals on artificial intelligence (AI) application for the estimation of kerf geometry and hole diameters for laser microcutting and laser micro-drilling operations. To this aim laser cutting and laser drilling operation were performed on NIMONIC 263 superalloy sheet, $0.38 \mathrm{~mm}$ in nominal thickness, by way of a $100 \mathrm{~W}$ fibre laser in modulated wave regime. Linear cuts and holes (by trepanning) were performed fixing the average power at $80 \mathrm{~W}$ and changing the pulse duration, the cutting speed, the focus depth and the laser path (the latter only for the drilling operations). Kerf width and the holed diameter, at the upper and downsides, were measured by digital microscopy. Different artificial neural networks (ANNs) were developed and tested to predict the kerf widths and the diameters (at the upper and downside). Two ANNs were addressed to the linear cutting process modelling; also, two further ANNs were developed for micro-drilling on the base of the linear cutting process features. The networks were trained with a subset of data containing the process conditions and the kerf/hole geometry. The ANN test was performed with the remaining data. The results show that ANNs can model the cut and hole geometry as a function of the process parameters. Moreover, the ANN trained with kerf geometry is more efficient. Therefore, a functional correlation between the kerf geometries achievable in the linear cutting process and micro-drilling was assessed.
\end{abstract}

Keywords Laser drilling $\cdot$ Laser cutting $\cdot$ Artificial neural networks $\cdot$ Cognitive systems

\section{Introduction}

Lately, manufacturing processes for material processing extensively apply laser technologies [1] due to some peculiar features of these methods such as precision, flexibility, low thermal impact on substrates and elevated productivity. These characteristics are critical, especially for all those sectors with tight quality requirements in terms of tolerances and metallurgical characteristics when no burr and recast layer are allowed.

Electrical discharge machining (EDM) represents state-ofthe art in micro-drilling systems. It allows the production of

Gabriele Baiocco

gabriele.baiocco@uniroma2.it

1 Department of Enterprise Engineering, University of Rome Tor Vergata, Via del Politecnico 1, 00133 Rome, Italy

2 Department of Engineering, University of Campania, Via Roma 29, 81031 Aversa, CE, Italy

3 CIRTIBS Research Centre, University of Naples Federico II, P.leTecchio 80, 80125 Naples, Italy accurate holes satisfying tight standard. Nevertheless, an extended process duration is needed, along with the use of polluting substances [2]. The laser beam machining (LBM) technology represents a viable alternative ensuring several benefits such as high productivity, process flexibility and geometrical accuracy [3-5]. Also, many substrates are suitable for this technology [6-11]. In general, two types of LBM processes were proposed: percussion drilling and trepanning drilling. The former provides for a laser beam passing through the workpiece producing a hole, while the latter cuts around a circumference. To perform the LBM, many studies in literature exploited Nd/YAG pulsed laser sources due to the high pulse energy that allows a high geometrical accuracy. However, several detrimental effects afflict the holes produced [12-14]. A viable alternative is represented by the fibre laser, a cheap and practical device to achieve high kerf quality [15-17]. Experimental tests assessed the influence of the process parameters on kerf geometry for a linear laser cutting process [18]. However, the LBM is a thermal process; the heat diffusion phenomena occurring during the machining heavily affect the kerf geometry like different cutting strategies (percussion or trepanning), which modify the heat input on the 
material at different depths and, therefore, the kerf edge geometry. Indeed, in trepanning micro-drilling processes, the same control variables affect the upper and lower kerf differently [19]. However, the knowledge of the hole geometry in trepanning micro-drilling as a function of the linear LBM kerf geometry would represent an enhancement in processes management and performance. In industrial environments, the kerf geometry evaluation of linear cuts is easier than micro-drilling characterization, since the latter requires the observation of the hole just in the middle.

Artificial intelligence (AI) and machine learning (ML) are recent fields that have already proved to have great potential to be a valuable and efficient aid in manufacturing process management [20-22]. Many industrial duties for function fittings, pattern classification and clustering tasks extensively exploit the cognitive system and artificial neural networks (ANNs). Indeed, they are reliable systems capable of modelling complex phenomena on the basis of empirical surveys [23]. ANNs are information processing structures that reproduce the biological neural system performance. Artificial neurons process a set of input variables, weighting and combining the data to achieve a set of output values. Following, the difference between output and target is calculated and the weight modified to minimize an error function [24-27]. In general, the ANNs are a versatile tool and find many applications in several fields such as decisionmaking processes [28-30], classification tasks [31, 32], phenomena modelling [33, 34], design optimization [35-38] and material characterization $[39,40]$. Concerning laser applications, several efforts were made to apply ML and ANNs for different tasks such as laser welding [41], laser engraving [42], additive manufacturing [43] and, in a broad sense, operational parameters optimization [44]. In [45], support vector machines were integrated with a geometric feature extraction process, a principal component analysis and a hidden Markov model to highlight crucial aspects of laser welding processes. In [46], molecular dynamics was applied in digital twin framework in cooperation with hidden Markov model for the simulation of femtolaser ablation processes. With specific respect to ANNs, many works were developed. In laser welding, they were applied with principal component analysis for real-time weld appearance estimation [47]. In [48], an ANN was applied to predict heat-affected zone and taper angle in laser percussion drilling. Furthermore, an artificial neural network aimed at predicting the holes' geometry in $\mathrm{Nd} / \mathrm{KGW}$ laser trepanning drilling is proposed in [49]. However, no application regarding kerf geometry prediction in fibre laser trepanning drilling was available.

Purpose of the work presented is the development of an AI system for the kerf geometry prediction in a fibre laser cutting processes. In the first step, two ANNs were developed to predict the upper and down kerf dimension of a linear cutting process as a function of the process parameters. However, due to the thermal nature of the process and different boundary
Table 1 NIMONIC 263 composition

Composition [Wt\%]

\begin{tabular}{llllll}
\hline $\mathrm{Co}$ & $\mathrm{Cr}$ & $\mathrm{Fe}$ & $\mathrm{Mn}$ & $\mathrm{Al}$ & $\mathrm{Si}$ \\
\hline $19.0-21.0$ & $19.0-21.0$ & $0-0.7$ & $0-0.6$ & $0-0.6$ & $0-0.4$ \\
$\mathrm{Cu}$ & $\mathrm{C}$ & $\mathrm{S}$ & $\mathbf{B}$ & $\mathbf{A g}$ & $\mathbf{B i}$ \\
$0-0.2$ & $0.04-0.08$ & $0-0.007$ & $0-0.005$ & $0-0.0005$ & $0-0.0001$ \\
\hline
\end{tabular}

conditions, the same laser parameters affect the micro-drilling differently. Therefore, two ANNs aimed at predicting the upper and lower diameter in a micro-drilling process were implemented. The training was performed respectively on the base of upper and down kerf of a linear cut, along with the main process parameters. Experimental tests were performed in several conditions monitoring the different kerf geometry achieved to acquire an experimental dataset. The results show how it is possible to find a functional correlation between the kerf geometries achievable in linear cutting process and micro-drilling.

\section{Materials and methods}

The experimental tests were performed on nickel alloy (NIMONIC 263) samples, whose composition is reported in Table 1, in the form of rolled sheets of $0.38-\mathrm{mm}$ thickness. A fibre laser (Red Power SP100C by SPI), whose characteristics are reported in Table 2, performs the laser cutting processes. The device exploits an optical fibre to transfer the laser radiation to a laser head (by HAAS LTI) mounted in a $3+1$ axis CNC system (Rofin finecut Y $340 \mathrm{M}$ ). It controls the laser source power, the geometric patterns and the beam speed. An external controller (MCA LCT3001) exerts the management of power and operational mode. When operating in a modulated mode, it allows the setting of pulse frequency and duration.

Table 2 RedPower SP100C by SPI laser characteristics

\begin{tabular}{lll}
\hline Parameter & Value & Unit \\
\hline Wavelength & 1090 & {$[\mathrm{~nm}]$} \\
Max. power & 80 & {$[\mathrm{~W}]$} \\
Mode operation & $\mathrm{CW}$ or MW & -- \\
Laser beam diameter & $5.0 \pm 0.5$ & {$[\mathrm{~mm}]$} \\
Full angle divergence & $>0.4$ & {$[\mathrm{mrad}]$} \\
Focal length & 50 & {$[\mathrm{~mm}]$} \\
Beam diameter at focal spot & $\approx 48$ & {$[\mu \mathrm{m}]$} \\
Nozzle diameter & 0.5 & {$[\mathrm{~mm}]$} \\
\hline
\end{tabular}


Table 3 Laser cutting control parameters

\begin{tabular}{llll}
\hline Pulse duration [ms] & $\begin{array}{l}\text { Cutting speed } \\
{[\mathrm{mm} / \mathrm{min}]}\end{array}$ & $\begin{array}{l}\text { Focus } \\
\text { depth }[\mathrm{mm}]\end{array}$ & Laser path \\
\hline $0.1-0.2-0.4$ & $200-400-600$ & $0-0.2$ & P1-P2 \\
\hline
\end{tabular}

The data required for the neural network training were achieved by performing experimental micro-drilling and linear cuts on the NIMONIC 263 samples. Both were performed with the same control factors and levels. The control parameters considered were pulse duration $(P d)$, cutting speed $(C s)$, focus depth $(F d)$ and laser path $(L p)$. The level values, reported in Table 3, resulted from preliminary activities aimed at assessing a range of the alloy machinability. The orbit variable refers to the number of passes that the beam spot made to realize the kerf in both the linear and circular configurations. Specifically, P1 and P2 express 1 and 2 passes of the laser spot to cut the NIMONIC 263 sheets, respectively. A schematic of the paths followed in the micro-drilling is reported in Fig. 1. After piercing the surface, the laser beam moves along the radius and then describes 1 or 2 orbits of $0.4-\mathrm{mm}$ diameter to produce a hole. The same occurs on the linear configuration, with the beam traversing the kerf distance once or twice.

Later, the samples were cut and polished up to a grit size of P2500 to highlight the kerf cross-section. The kerf geometry was evaluated by digital microscopy (KH-8700 by Hirox), according to the UNI EN 12584 2001 and ISO 9013:2002 standard as described in [20]. The geometric variables measured in this configuration were upper kerf " $U_{k}$ " and down kerf " $D_{k}$," as represented schematically in Fig. 2. The micro-drilling geometry characterization was performed following the ISO 12181-1:2011 standard, as described in [21]. The procedure leads to the definition of a mean diameter of the hole produced on the upper and the lower surfaces of the samples, respectively indicated as $D_{\text {in }}$ and $D_{\text {out }}$.

As stated before, 4 ANNs were developed for the prediction of $U_{k}, D_{k}, D_{\text {in }}$ and $D_{\text {out }}$. They are indicated in this paper as, respectively, Uk-Net, Dk-Net, Din-Net and Dout-Net. In particular, backpropagation feedforward neural networks were

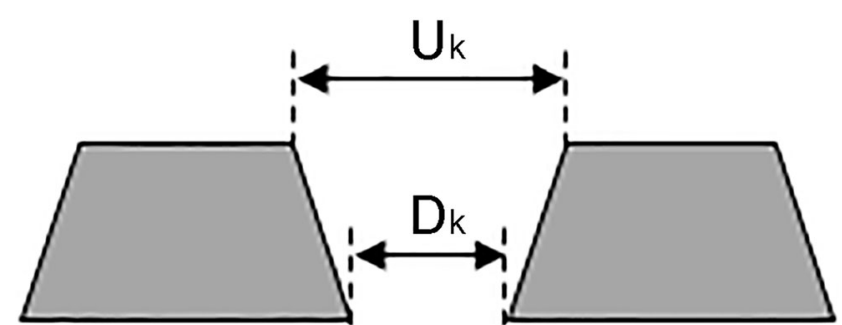

Fig. 2 Schematic of a linear kerf cross-section

implemented in MATLAB environment and trained with the experimental data achieved. During the training, several configurations were considered. The variables involved were the main structure parameters such as the number of hidden layers, number of neurons, transfer functions and training algorithm. No optimization was involved in network size assessment, which was determined through a trial and error process evaluating the means square error (MSE), as reported in Eq. 1.

$M S E=\frac{1}{n} \sum_{i=1}^{n}\left(t_{i}-x_{i}\right)^{2}$

For the sake of briefness, only the networks offering the best prediction, which structures and training parameters are resumed in Table 4, are reported and discussed. The network performances were accounted by means of three indicators, which are mean percentage error $x_{m}$ (Eq. 2), standard deviation $x_{d v . s t d .}$ (Eq. 3) and linear least square regression.

$x_{m}=\left(\frac{1}{n} \sum_{i=1}^{n} t_{i}-x_{i}\right) 100$

$x_{d v . s t d .}=\sqrt{\frac{\sum_{i=1}^{n}\left(t_{i}-x_{i}\right)^{2}}{n}}$

In Eq. 1 and following, $n$ represents the instance s, $x_{i}$ the network output and $t_{i}$ the target output. For both Uk-Net and Dk-Net, proposed in Figs. 3 and 4, 4 input neurons stand for the process parameters considered in the study (i.e. $\mathrm{Pd}, \mathrm{Cf}, \mathrm{Fd}$ and Lp). Also, they have two hidden layers. While in Uk-Net, they count, respectively, 10 and 4 neurons, in Dk-Net there are
Fig. 1 Path followed for the microdrilling processes
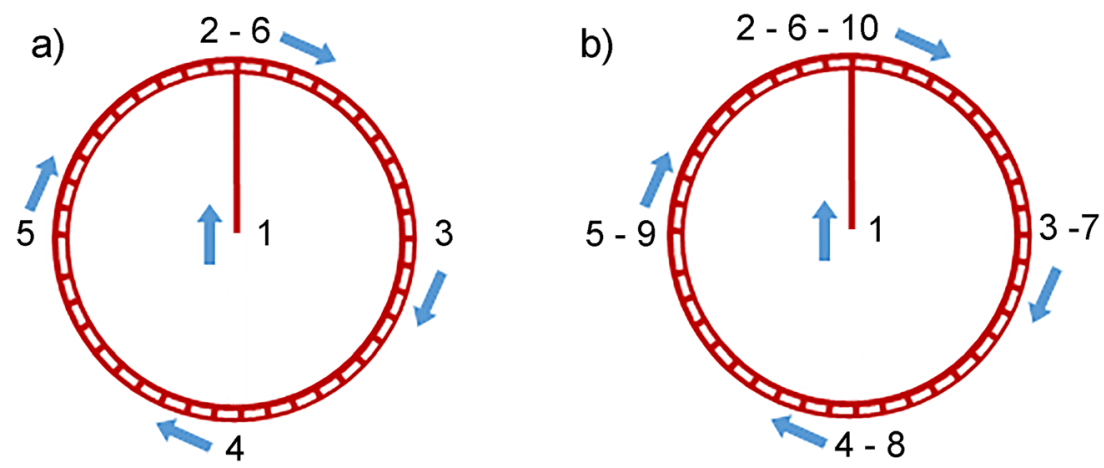
Table 4 Uk-Net, Dk-Net, DinNet and Dout-Net structure and training parameters

\begin{tabular}{llclc}
\hline ANN parameters & Uk-Net & Dk-Net & Din-Net & Dout-Net \\
\hline Input & Pd; Cf; Fd; Lp & & Pd; Cf; Fd; Lp; Uk & Pd; Cf; Fd; Lp; Dk \\
Output & \multicolumn{1}{c}{ Uk } & Dk & Din & Dout \\
Hidden layers & 2 & & 1 & \\
Neuron number & $4-10-4-1$ & $4-8-3-1$ & $5-7-1$ & \\
Transfer function & Logsimoidal-tansigomoidal-linear & Logsimoidal-linear & \\
Training algorithm & Trainlm & Traingd & \\
Net goal (min. MSE) & $1 \mathrm{e}-18$ & $1 \mathrm{e}-18$ & \\
Max. epochs number & 35,000 & $1 \mathrm{e}-10$ & 35,000 & \\
Min. gradient & & $1 \mathrm{e}-10$ & \\
\hline
\end{tabular}

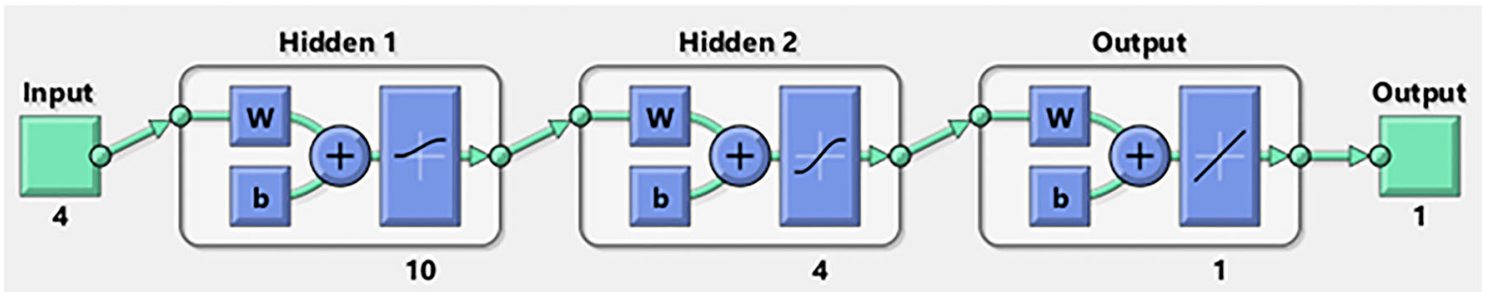

Fig. 3 Uk-Net structure. In the figure, the numbers represent the adopted neurons

8 and 3 neurons. The single neuron of the output layer stands for the kerf geometry investigated. The transfer functions exploited for the connection of layers were, from the input to the output layer, respectively, the logsimoidal, the tansigomoidal and the linear transfer function.

Considering Din-Net and Dout-Net, represented in Fig. 5, both the networks have 5 neurons standing for the process and geometry control variables of the kerfs. Specifically, $U_{k}$ and $\mathrm{D}_{\mathrm{k}}$ were exploited in the training of, respectively, Din-Net and Dout-Net. The hidden layer has the same neurons numbers in Din-Net and Dout-Net, which are 7. A single neuron in the output layer stands for the kerf geometry in the micro-drilling process. The transfer functions exploited for the layers' connection were, from the input to the output layer, respectively, logsimoidal and linear transfer function.

For each combination of control factors and levels, four replicates were performed for a total of 144 experimental tests. Then, the mean value and standard deviation were calculated to assess the presence of outliers. Also, the mean values calculated for each set of replicates was assumed as the actual value of the kerf geometry achievable in a given condition. Therefore, the datasets exploited for the ANN training were composed of 36 examples. The division percentage between the training and validation set of the experimental data set was and 80-20. Therefore, the validation set counts 7 instances. They were submitted to the network following the training phase to test the ANN effectiveness in predicting the kerf geometry.

Since a low number of examples were used in the trial, the data needed for the training was carefully selected. The procedure aim was to give the broadest training range possible. Therefore, the instances with the boundary level of each control factor were exploited in the training set. Instead, intermediate values were selected for the ANNs validation. Indeed, validation instances outside the boundaries of a training set may be wrongly interpreted by an ANN. In fact, such values fall outside the range for which the weights among the neuron connections have been trained.

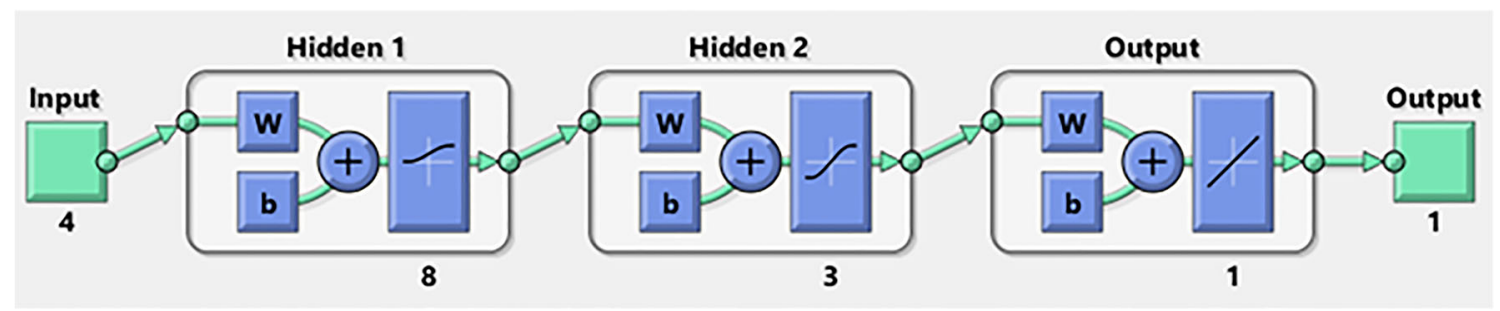

Fig. 4 Dk-Net structure. In the figure, the numbers represent the adopted neurons 


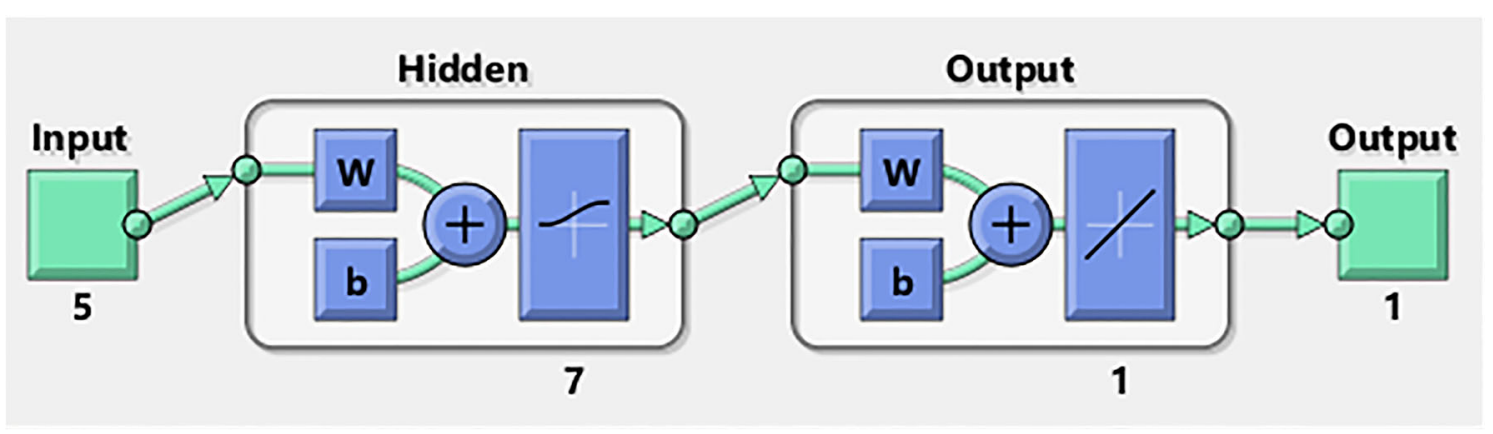

Fig. 5 Schematic of Din-Net and Dout-Net structures
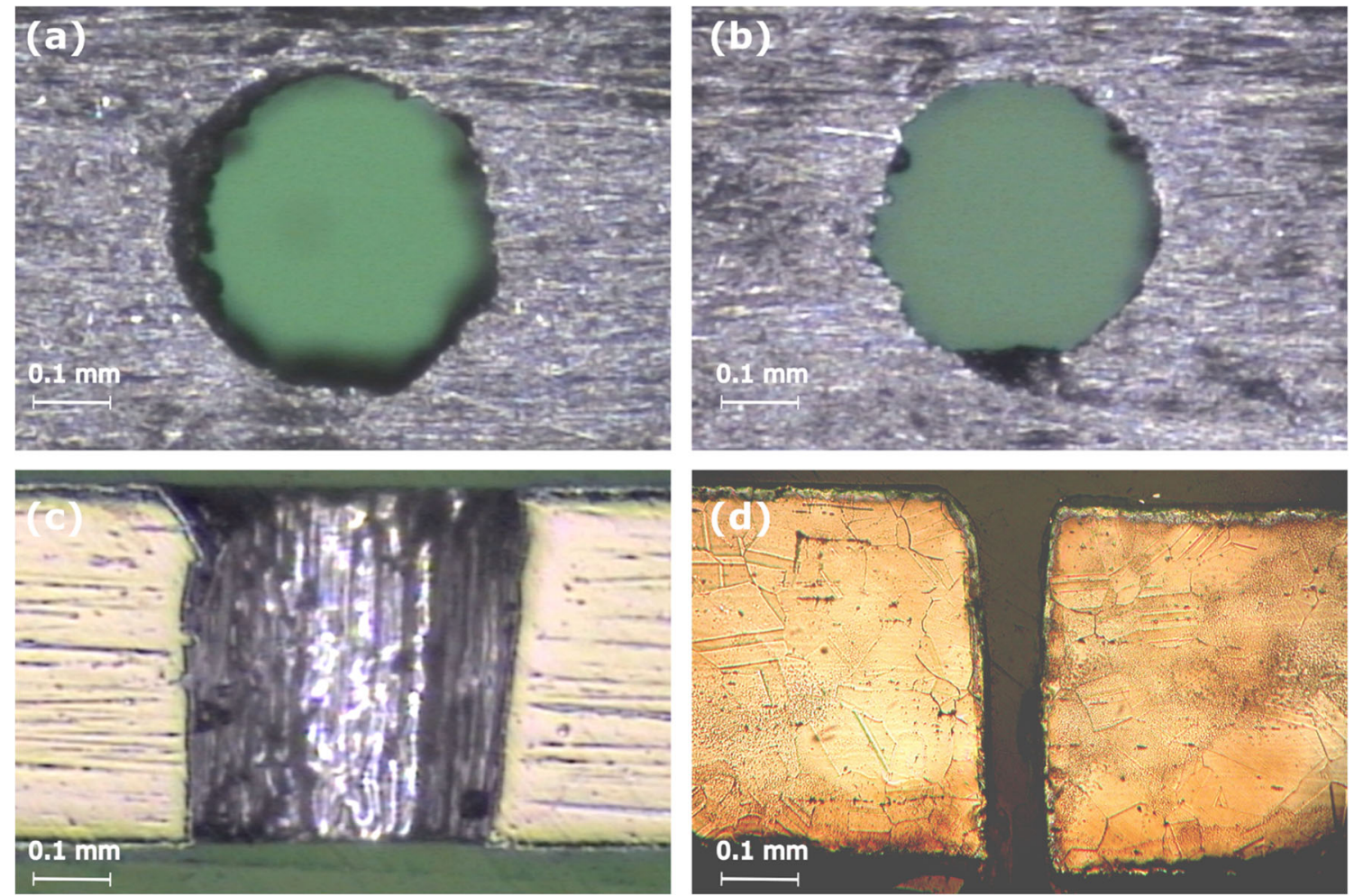

Fig. 6 Images of hole and linear cut performed at $\mathrm{Pd}=0.2 \mathrm{~ms}, \mathrm{Cs}=400 \mathrm{~mm} / \mathrm{min}, \mathrm{Fd}=0.2 \mathrm{~mm}, \mathrm{Lp}=\mathrm{M} 1$ : a hole entry, $\mathbf{b}$ hole exit, $\mathbf{c}$ hole section, $\mathbf{d}$ kerf section

$M S E=\frac{1}{n} \sum_{i=1}^{n}\left(t_{i}-x_{i}\right)^{2}$

Although the heat diffusion in the linear configuration is less tangled than in micro-drilling, due to the simple geometry of the cut, the ANNs are more complex. Indeed, these networks present a higher number of hidden layers and neurons.
However, the micro-drilling ANNs have 1 more input neuron that refers to the linear cut geometry. It is a critical parameter and a precious aid for achieving predictions about the kerf characterization. Also, this confirms how the linear kerf may be a valuable starting point for a micro-drilling kerf characterization.
Table 5 Measured geometric kerf features

\begin{tabular}{lllll}
\hline & Average value & Min. value & Max. value & Standard deviation \\
\hline Uk & 0.0991 & 0.0820 & 0.1144 & 0.0028 \\
Dk & 0.0423 & 0.0332 & 0.0517 & 0.0051 \\
Din & 0.3941 & 0.3810 & 0.4044 & 0.0023 \\
Dout & 0.3327 & 0.3215 & 0.3431 & 0.0034 \\
\hline
\end{tabular}




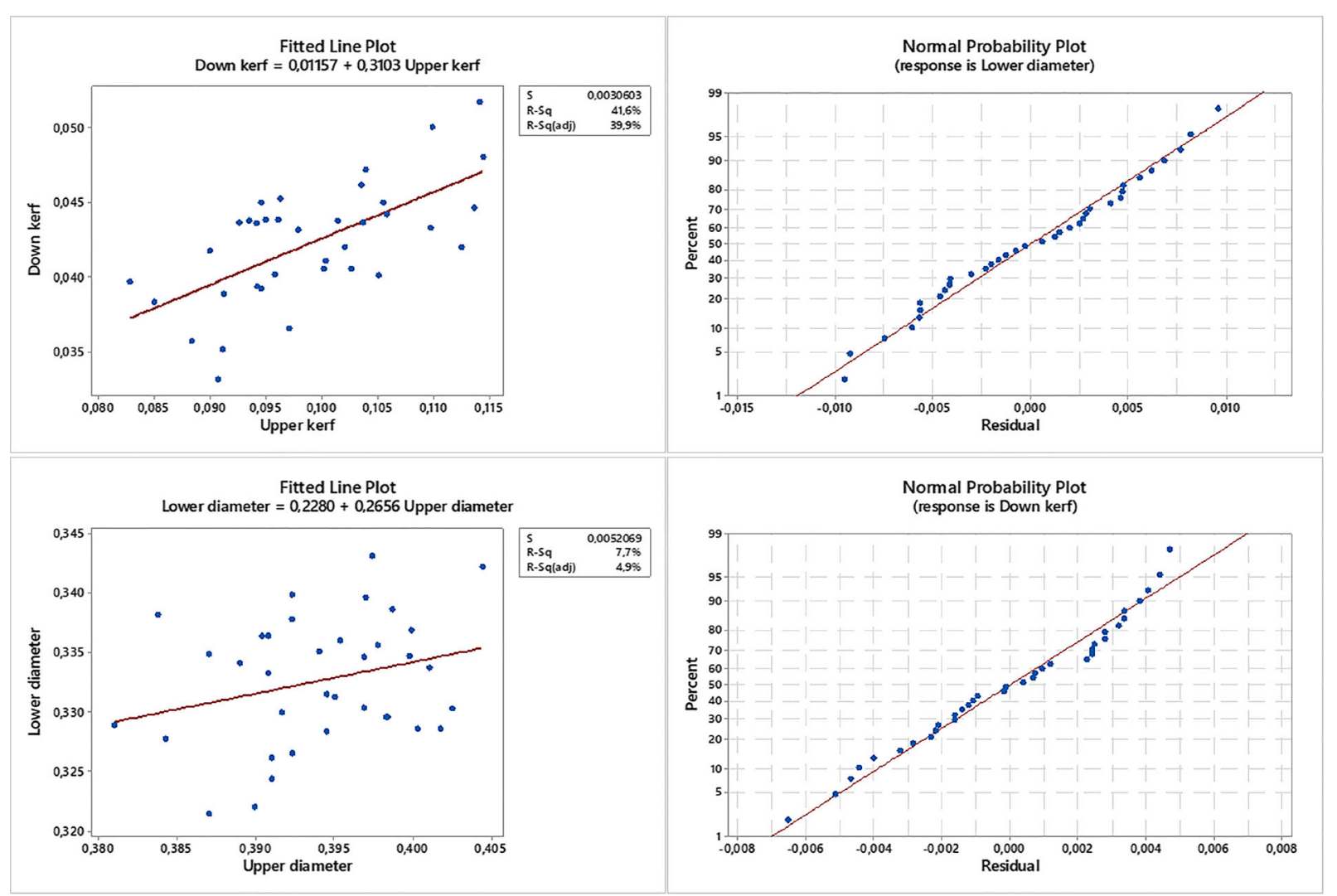

Fig. 7 Linear regression for Uk vs Dk and Din vs Dout
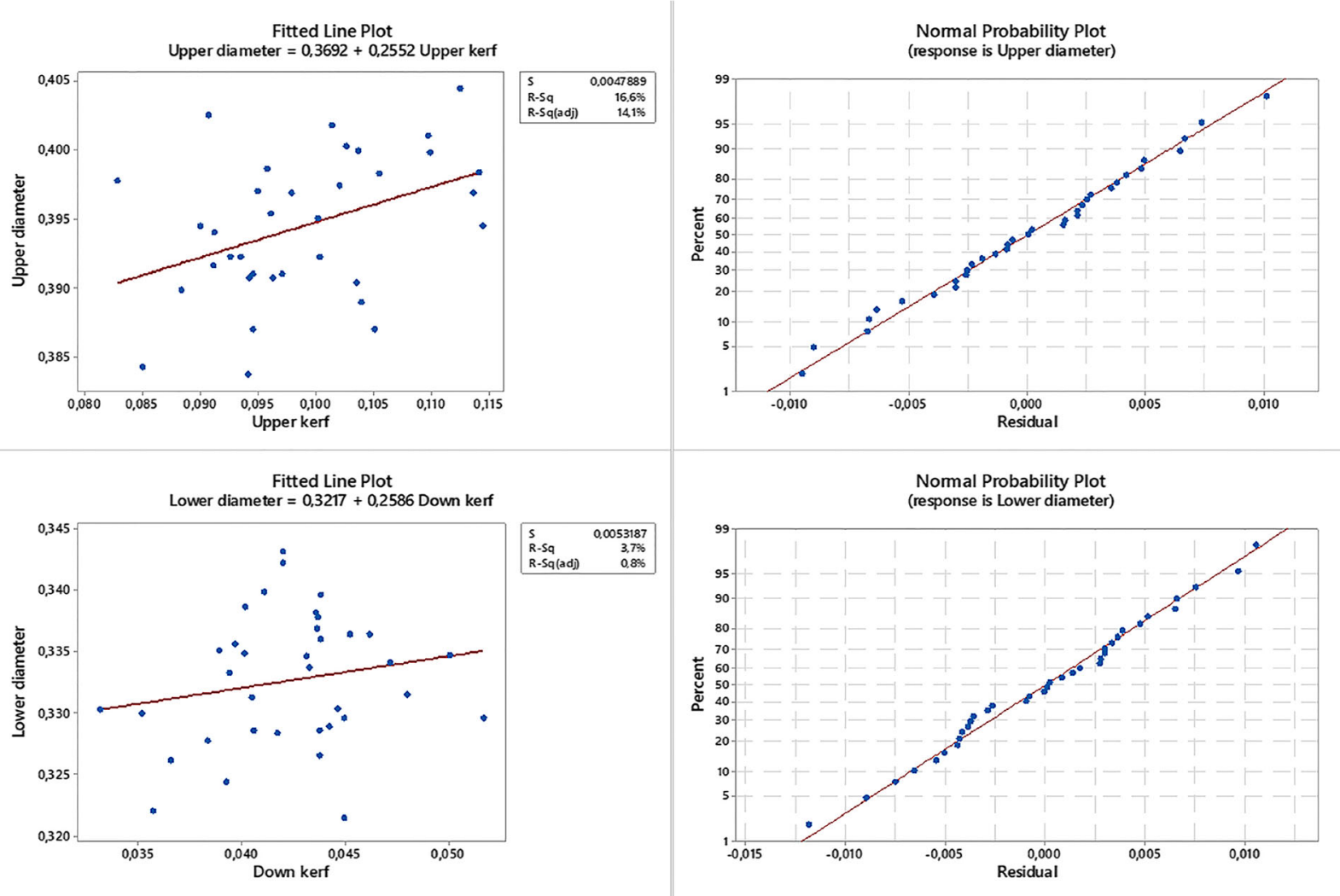

Fig. 8 Linear regression for $U_{k}$ vs $D_{\text {in }}$ and $D k$ vs $D_{\text {out }}$ 
Fig. 9 Uk-Net and Dk-Net percentage error

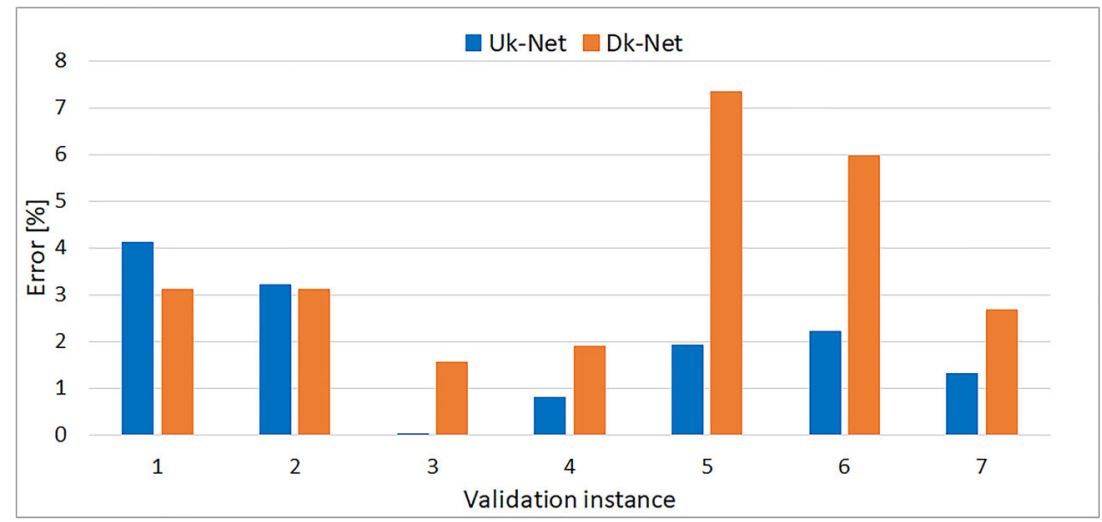

\section{Results and discussion}

The experimental activities performed led to the production of micro-drilled holes on the surface of the NIMONIC 263 samples. The main geometrical features of the kerf in both the circular and linear configurations were assessed for each combination of control factors and levels. Representative samples cut and drilled are reported in Fig. 6. Therefore, a statistical evaluation, whose results are reported in Table 5, was performed. The mean values gauged for each combination of factors vary in a short range. Also, Uk and Dk are in the order of the hundredth of a millimetre. Instead, the Din and Dout values in the micro-drilling were grater of one order of magnitude. Indeed, the heat spreading into the bulk is greater in linear cutting than in micro-drilling since, in the former configuration, the heat spreads in a theoretically infinite plane. In contrast, in the latter configuration, the heat spreading inside

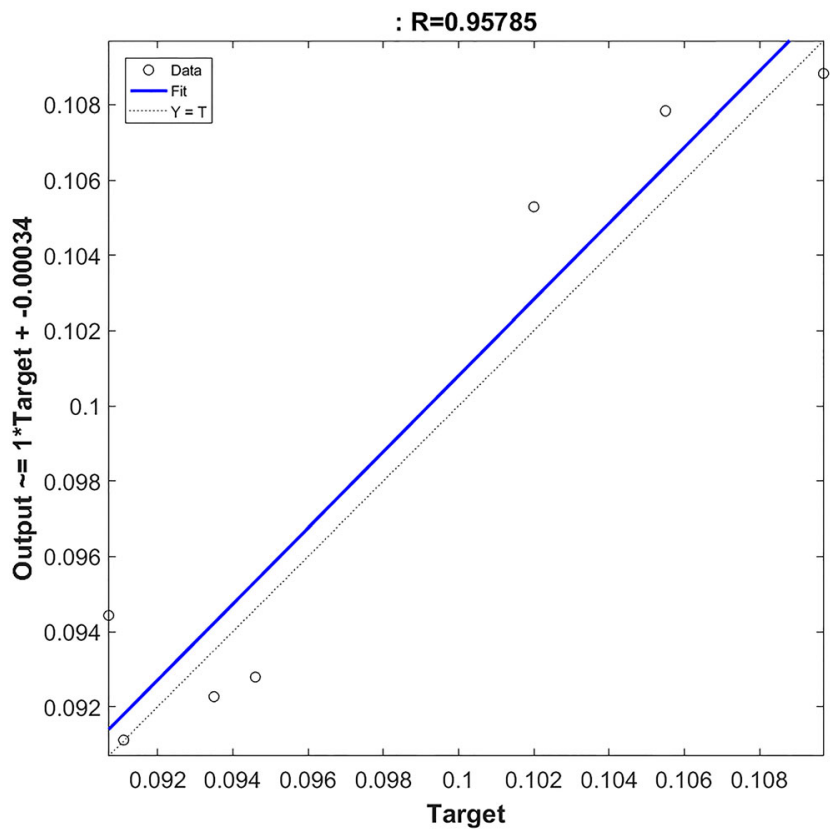

Fig. 10 Linear regression for Uk-Net predictions the hole section gives a continuous thermal contribution that enlarges the kerf geometry. Despite the difference in kerf values, all the geometrical feature measured have a standard deviation in the order of $10^{-3}$. Therefore, the mean values were assumed as the actual kerf values achievable with given process parameters. Also, it is worth noting that the standard deviation is higher in the $\mathrm{D}_{\mathrm{k}}$ and $\mathrm{D}_{\text {out }}$. Indeed, the heat diffusion has a more severe influence in defining the lower geometry parameters since the heat must go through the bulk.

In a first attempt to correlate the geometrical feature, the $U_{k}$ vs $D_{k}$ and $D_{i n} v s D_{\text {out }}$ linear regression were produced. The results are reported in Fig. 7. In the first case, it is possible to find a linear correlation, net of variations due to diffusion phenomena aleatory and cutting parameters. However, the same does not occur for the other combinations. Also, a linear regression was performed considering $U_{k}$ vs $D_{\text {in }}$ and $D_{k}$ vs $\mathrm{D}_{\text {out }}$. As highlighted in Fig. 8, to a maximum or a minimum of

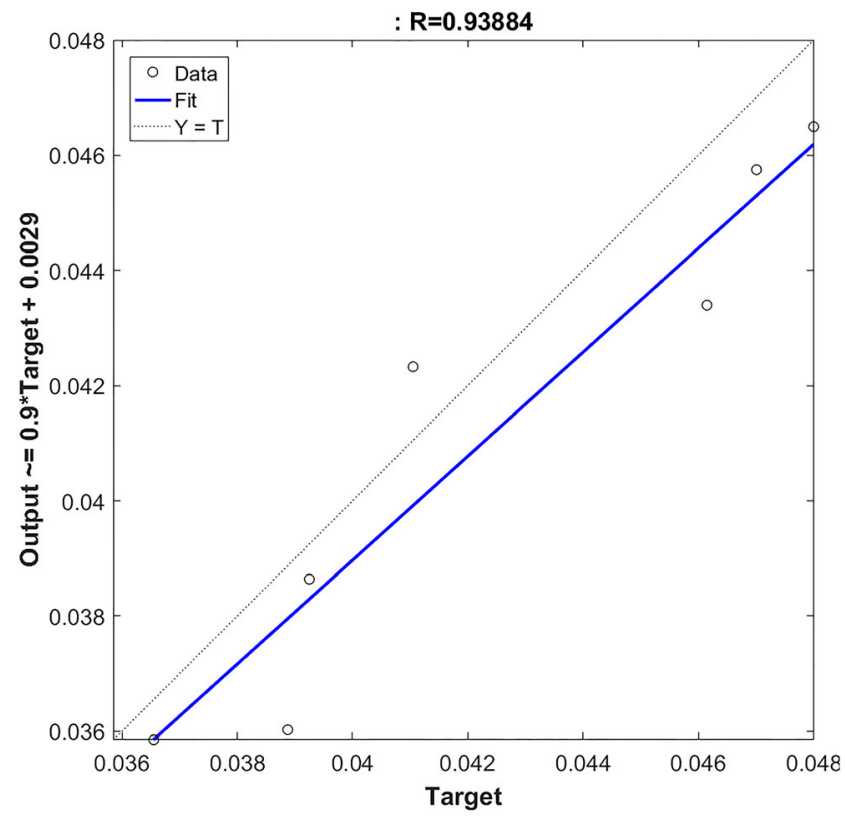

Fig. 11 Linear regression for Dk-Net predictions 
Fig. 12 Din-Net and Dout-Net validation results

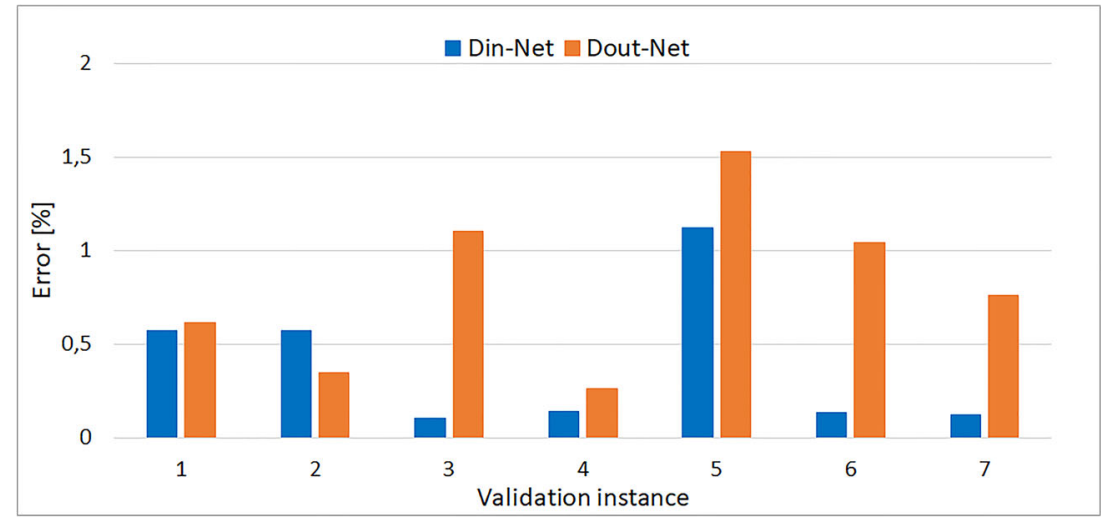

$\mathrm{U}_{\mathrm{k}}$ and $\mathrm{D}_{\mathrm{k}}$ do not correspond a brink value of Din and Dout. It led to think that diffusion phenomenon affects laser cuttings as a function of local bulk properties and, depending on cutting configuration, produces different effects on the kerf geometry. However, the physics behind the phenomena are strongly non-linear; therefore, an AI model is necessary to express this correlation.

The results achieved in the prediction of $U_{k}$ and $D_{k}$ are reported in Fig. 9 in terms of percentage error. The training led to achieving precise modelling of the linear cut geometry, with a mean error and a standard deviation, respectively, of 1.94 and $1.4 \%$ for Uk-Net and 3.66 and $2.15 \%$ for Dk-Net. The high performance is highlighted by analysing the linear regression of the prediction vs the target, reported in Figs. 10 and 11. Indeed, both the network show an outstanding R-square which was respectively of about 0.96 and 0.94 . The results achieved in the prediction

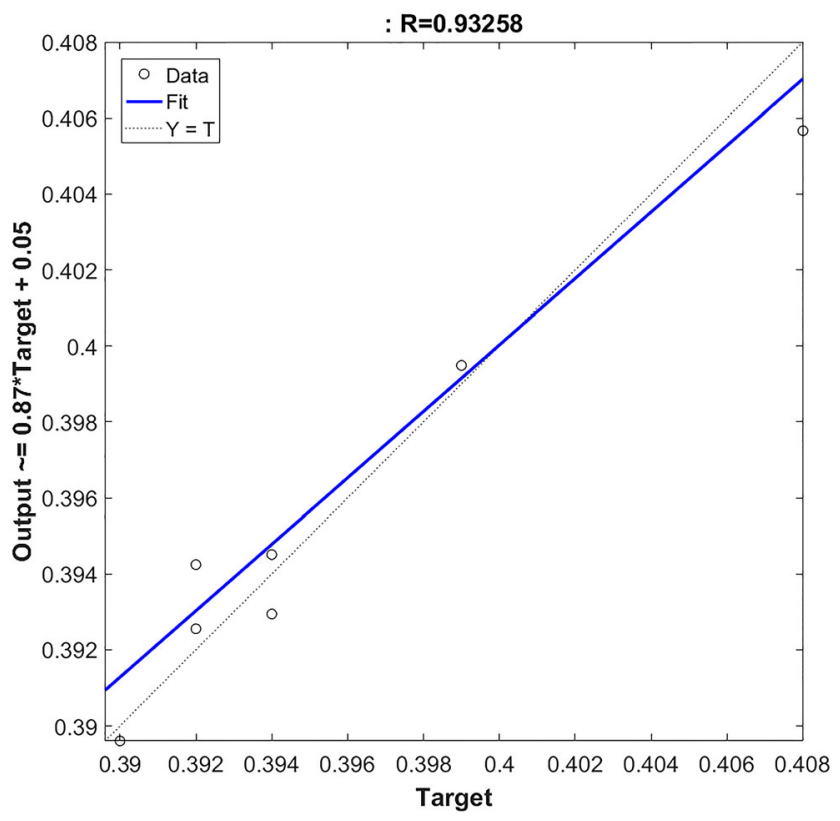

Fig. 13 Linear regression for Din-Net predictions of $D_{\text {in }}$ and $D_{\text {out }}$ are reported in Fig. 12. The Din-Net training led to the implementation of accurate prediction network. Indeed, the validation percentage error is of about $0.39 \%$ and dispersion of about $0.38 \%$. Dout-Net also achieves high accuracy in results prediction with a mean error of $0.80 \%$ and a standard deviation of about $0.45 \%$. However, an increased difference between the network prediction ability is noticeable by the linear regressions, reported in Figs. 13 and 14, respectively, for Up-Net and Down-Net. Indeed, Up-Net is characterized by a regression coefficient of about 0.93 against of 0.73 achieved by Down-net. Although the latter allows a minor generalization ability, the behaviour is heavily influenced by the dataset values dispersion obtained in the down kerf measurement. However, the differences evaluated are in the order of few or tens microns which is still an accuracy compatible with the thigh standard available for the

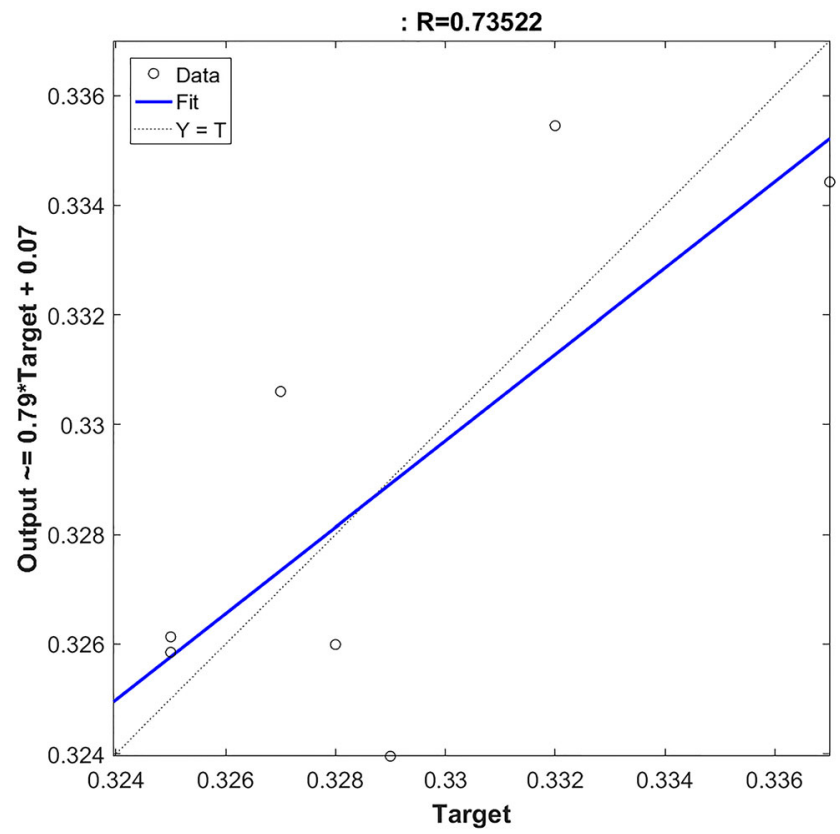

Fig. 14 Linear regression for Dout-Net predictions 
Table 6 ANN performance estimators

\begin{tabular}{llll}
\hline ANN & $\mathrm{R}^{2}$ & Mean E\% & E\% standard deviation \\
\hline Uk-Net & 0.96 & 1.94 & 1.40 \\
Dk-Net & 0.94 & 3.66 & 2.15 \\
Din-Net & 0.93 & 0.39 & 0.38 \\
Dout-Net & 0.73 & 0.80 & 0.45 \\
\hline
\end{tabular}

micro-drilling processes. Also, it demonstrates that it is possible to relate the geometrical kerf feature obtainable in a linear cutting to the geometry achievable in microdrilling. A resume of the ANN performance estimators is reported in Table 6.

\section{Conclusion}

The present paper deals with the implementation of ANNs aimed at the prediction of the geometrical features achievable during laser linear cutting and micro-drilling. Particular interest lied in achieving a correlation between the geometries of the two processes. Therefore, for the linear cutting processes, only the laser parameters were investigated. Instead, for the micro-drilling, the kerfs produced in the linear cuts were also considered. Experimental tests aimed at evaluating the different kerf geometries were performed. The outputs of interest were upper and down kerf for linear cutting while the upper and the lower diameter in micro-drilling. The statistical investigation showed how the laser processes performed were extremely reliable. As a matter of facts, a low standard deviation was achieved for each combination of the control levels. However, it grows when the kerf characteristics on the lower surface are evaluated. Being the laser cutting a thermal process, the diffusion phenomena occurring inside the bulk heavily affect the kerf features. Indeed, heat diffusion is affected by the local condition of the material which cannot be thoroughly controlled. Furthermore, the ANNs implemented for the linear process (Uk-Net and Dk-Net) needed a more complex structure, with respect to the micro-drilling ANNs (Din-Net and Dout-Net) in terms of hidden layers and neuron number. However, the formers have an input neuron less than the latters. It stands for the linear kerfs achieved and represents a precious parameter for the neural modelling of the laser micro-drilling process as it allows a reduction of the complexity of the network. However, both the micro-drilling and linear cutting network produced outstanding results in kerf prediction. In particular, the highest mean error is generated in $\mathrm{D}_{\text {out }}$ prediction that is the harshest condition, and it is less than $4 \%$. Therefore, two goals were reached: the kerf prediction as a function of the essential lasers' parameters and a correlation between the linear and the circular kerf for the same control parameters, which was the main focus of the investigation.

Funding Open access funding provided by Università degli Studi di Roma Tor Vergata within the CRUI-CARE Agreement. This research did not receive any specific grant from funding agencies in the public, commercial, or not-for-profit sectors.

Availability of data and material The datasets generated during and/or analysed during the current study are available from the corresponding author on reasonable request.

Code availability The software code generated during the current study is available from the corresponding author on reasonable request.

\section{Declarations}

Conflict of interest The authors declare that they have no known competing financial interests or personal relationships that could have appeared to influence the work reported in this paper.

Open Access This article is licensed under a Creative Commons Attribution 4.0 International License, which permits use, sharing, adaptation, distribution and reproduction in any medium or format, as long as you give appropriate credit to the original author(s) and the source, provide a link to the Creative Commons licence, and indicate if changes were made. The images or other third party material in this article are included in the article's Creative Commons licence, unless indicated otherwise in a credit line to the material. If material is not included in the article's Creative Commons licence and your intended use is not permitted by statutory regulation or exceeds the permitted use, you will need to obtain permission directly from the copyright holder. To view a copy of this licence, visit http://creativecommons.org/licenses/by/4.0/.

\section{References}

1. Chryssolouris G (2013) Laser machining: theory and practice. Springer Science \& Business Media, Berlin

2. Genna S, Leone C, Palumbo B, Tagliaferri F (2015) Statistical approach to fiber laser microcutting of NIMONIC® C263 superalloy sheet used in effusion cooling system of aero engines. Procedia CIRP 33:520-525. https://doi.org/10.1016/j.procir.2015.06.067

3. Ashkenasia D, Kaszemeikata T, Muellera N, Dietricha R, Eichlera HJ, Illinga G (2011) Laser trepanning for industrial applications. Phys Procedia 12:323-331. https://doi.org/10.1016/j.phpro.2011. 03.140

4. Jacobs P (2008) Aerospace applications of precision trepanning. ICALEO. https://doi.org/10.2351/1.5061308

5. Romoli L, Rashed CAA, Fiaschi M (2014) Experimental characterization of the inner surface in micro-drilling of spray holes: a comparison between ultrashort pulsed laser and EDM. Opt Laser Technol 56:35-42. https://doi.org/10.1016/j.optlastec.2013.07.010

6. Petronić S, Kovačević G, Milosavljević A, Milosavljević A, Sedmak A (2012) Microstructural changes of Nimonic-263 superalloy caused by laser beam action. Phys Scr T149:014080. https:// doi.org/10.1088/0031-8949/2012/T149/014080

7. Leone C, Genna S, Caggiano A, Tagliaferri V, Molitierno R (2016) Influence of process parameters on kerf geometry and surface 
roughness in Nd:YAG laser cutting of $\mathrm{Al} 6061 \mathrm{~T} 6$ alloy sheet. Int J Adv Manuf Technol 87:2745-2762. https://doi.org/10.1007/ s00170-016-8667-4

8. Astarita A, Genna S, Leone C, Memola Capece Minutolo F, Paradiso V, Squillace A (2013) Ti-6Al-4 V Cutting by $100 \mathrm{~W}$ fibre laser in both CW and modulated regime. Key Eng Mater 554-557: 1835-1844. https://doi.org/10.4028/www.scientific.net/KEM.554557.1835

9. Lutey AHA, Fortunato A, Ascari A, Carmignato S, Leone C (2015) Laser cutting of lithium iron phosphate battery electrodes: characterization of process efficiency and quality. Opt Laser Technol 65: 164-174. https://doi.org/10.1016/j.optlastec.2014.07.023

10. Tonshoff HK, Emmelmann C (1989) Laser cutting of advanced ceramics. CIRP Ann 38:219-222. https://doi.org/10.1016/S00078506(07)62689-4

11. Leone C, Genna S, Tagliaferri V (2014) Fibre laser cutting of CFRP thin sheets by multi-passes scan technique. Opt Lasers Eng 53:4350. https://doi.org/10.1016/j.optlaseng.2013.07.027

12. Thawari G, Sarin Sundar JK, Sundararajan G, Joshi SV (2005) Influence of process parameters during pulsed Nd:YAG laser cutting. of nickel-base superalloys. J Mater Process Technol 170:229239. https://doi.org/10.1016/j.jmatprotec.2005.05.021

13. Morace RE, Leone C, De Iorio I (2005) Cutting of thin metal sheets using Nd:YAG lasers with different pulse duration. Proceedings of SPIE - Int Soc Opt Eng. https://doi.org/10.1117/12.661182

14. Rao R, Yadava V (2009) Multi-objective optimization of Nd:YAG laser cutting of thin superalloy sheet using grey relational analysis with entropy measurement. Opt Laser Technol 41:922-930. https:// doi.org/10.1016/j.optlastec.2009.03.008

15. Baumeister M, Dickmann K, Hoult T (2006) Fiber laser microcutting of stainless steel sheets. Appl Phys A Mater Sci Process 85(2):121-124. https://doi.org/10.1007/s00339-006-3687-9

16. Dausinger F (2000) Precise drilling with short pulsed lasers. Proceedings of SPIE - Int Soc Opt Eng. https://doi.org/10.1117/ 12.377015

17. Kling R, Dijoux M, Romoli L, Tantussi F, Sanabria J, Mottay E (2013) Metal micro drilling combining high power femtosecond laser and trepanning head. Proceedings of SPIE - Int Soc Opt Eng. https://doi.org/10.1117/12.2002083

18. Genna S, Tagliaferri F, Leone C, Palumbo B, De Chiara G (2017) Experimental study on fiber laser microcutting of Nimonic 263 superalloy. Procedia CIRP 62:281-286. https://doi.org/10.1016/j. procir.2016.06.109

19. Tagliaferri F, Genna S, Leone C, Palumbo B, De Chiara G (2017) Experimental study of fibre laser microdrilling of aerospace superalloy by trepanning technique. Int J Adv Manuf Technol 93:32033210. https://doi.org/10.1007/s00170-017-0773-4

20. Makridakis S (2017) The forthcoming Artificial Intelligence (AI) revolution: Its impact on society and firms. Futures 90:46-60. https://doi.org/10.1016/j.futures.2017.03.006

21. Cheng K, Bateman RJ (2008) e-Manufacturing: characteristics, applications and potentials. Prog Nat Sci 18(11):1323-1328. https:// doi.org/10.1016/j.pnsc.2008.03.027

22. Alcácer V, Cruz-Machado V (2019) Scanning the Industry 4.0: a literature review on technologies for manufacturing systems. Eng Sci Technol Int J 22(3):899-919. https://doi.org/10.1016/j.jestch. 2019.01.006

23. Basheer I, Hajmeer M (2000) Artificial neural networks: fundamentals, computing, design, and application. J Microbiol Methods 43: 3-31. https://doi.org/10.1016/S0167-7012(00)00201-3

24. O'Regan G (2012) A brief history of computing. Springer, London

25. Rajasekaran S, Pai GAV (2003) Neural networks, fuzzy logic and genetic algorithm: synthesis and applications. Hoepli, Milan

26. Hussain DMA, Rajput AQK, Chowdhry BS, Gee Q (2008) Wireless networks information processing and systems. Springer, Berlin
27. Wu CL, Chau KW, Li YS (2009) Methods to improve neural network performance in daily flows prediction. J Hydrol 372(1-4):80 93. https://doi.org/10.1016/j.jhydrol.2009.03.038

28. Walczak S, Velanovich V (2018) Improving prognosis and reducing decision regret for pancreatic cancer treatment using artificial neural networks. Decis Support Syst 106:110-118. https://doi.org/ 10.1016/j.dss.2017.12.007

29. Anagnostou T, Remzi M, Djavan B (2003) Artificial neural networks for decision-making in urologic oncology. Rev Urol 5:1521. https://doi.org/10.1016/s0302-2838(03)00133-7

30. Yu X, Ye C, Xiang L (2016) Application of artificial neural network in the diagnostic system of osteoporosis. Neurocomputing 214:376-381. https://doi.org/10.1016/J.NEUCOM.2016.06.023

31. Kılıç K, Boyacı İH, Köksel H, Küsmenoğlu İ (2007) A classification system for beans using computer vision system and artificial neural networks. J Food Eng 78:897-904. https://doi.org/10.1016/ J.JFOODENG.2005.11.030

32. Bakhshipour A, Jafari A (2018) Evaluation of support vector machine and artificial neural networks in weed detection using shape features. Comput Electron Agric 145:153-160. https://doi.org/10. 1016/j.compag.2017.12.032

33. Bre F, Gimenez JM, Fachinotti VD (2018) Prediction of wind pressure coefficients on building surfaces using artificial neural networks. Energy Build 158:1429-1441. https://doi.org/10.1016/J. ENBUILD.2017.11.045

34. Trovalusci F, Ucciardello N, Baiocco G, Tagliaferri F (2019) Neural network approach to quality monitoring of injection molding of photoluminescent polymers. Appl Phys A Mater Sci Process 125. https://doi.org/10.1007/s00339-019-3067-x

35. Silva N, Ferreira LMDF, Silva C, Magalhães V, Neto P (2017) Improving supply chain visibility with artificial neural networks. Procedia Manuf 11:2083-2090. https://doi.org/10.1016/J. PROMFG.2017.07.329

36. Kim SH, Vu TM, Pyeon CH (2017) A preliminary study on applicability of artificial neural network for optimized reflector designs. Energy Procedia 131:77-85. https://doi.org/10.1016/J.EGYPRO. 2017.09.478

37. Lucignano C, Montanari R, Tagliaferri V, Ucciardello N (2010) Artificial neural networks to optimize the extrusion of an aluminium alloy. J Intell Manuf 21:569-574. https://doi.org/10.1007/ s10845-009-0239-0

38. Almonti D, Baiocco G, Tagliaferri V, Ucciardello N (2019) Artificial neural network in fibres length prediction for high precision control of cellulose refining. Mater. 12. https://doi.org/10. 3390/ma12223730

39. Costanza G, Tata ME, Ucciardello N (2006) Superplasticity in PbSn60: Experimental and neural network implementation. Comput Mater Sci 37:226-233. https://doi.org/10.1016/J. COMMATSCI.2005.06.009

40. Baiocco G, Ucciardello N (2019) Neural network implementation for the prediction of secondary phase precipitation and mechanical feature in a duplex stainless steel. Appl Phys A Mater Sci Process 125. https://doi.org/10.1007/s00339-018-2312-z

41. Missori S, Sili A, Ucciardello N (2008) Process parameters optimization of laser beam welded joints by neural network. Mater Manuf Process 23:169-174. https://doi.org/10.1080/1042691070177469

42. Rahimi MH (2019) Modelling and optimization of laser engraving qualitative characteristics of $\mathrm{Al} \mathrm{SiC} \mathrm{composite} \mathrm{using} \mathrm{response} \mathrm{sur-}$ face methodology and artificial neural networks. Opt Laser Technol 112(15):65-76. https://doi.org/10.1016/j.optlastec.2018.10.058

43. Marrey M, Malekipour E, El-Mounayri H, Eric J, Faierson A (2019) Framework for optimizing process parameters in powder bed fusion (PBF) process using artificial neural network (ANN). Procedia Manuf 34:505-515. https://doi.org/10.1016/j.promfg. 2019.06.214 
44. Adineh VR, Aghanajafi C, Dehghan GH, Jelvani S (2008) Optimization of the operational parameters in a fast axial flow $\mathrm{CW} \mathrm{CO} 2$ laser using artificial neural networks and genetic algorithms. Opt Laser Technol 40(8):1000-1007. https://doi.org/10. 1016/j.optlastec.2008.03.003

45. Stavropoulos P, Papacharalampopoulos A, Stavridis J, Sampatakakis K (2020) A three-stage quality diagnosis platform for laser-based manufacturing processes. Int J Adv Manuf Technol 110(11):2991-3003. https://doi.org/10.1007/s00170-020-05981-9

46. Stavropoulos P, Papacharalampopoulos A, Athanasopoulou L (2020) A molecular dynamics based digital twin for ultrafast laser material removal processes. Int J Adv Manuf Technol 108:413442. https://doi.org/10.1007/s00170-020-05387-7

47. Zhang Y, Gao X, Katayama S (2015) Weld appearance predictionwith BP neural network improved by genetic algorithm during disklaser welding. J Manuf Syst 34:53-59. https://doi.org/ 10.1016/j.jmsy.2014.10.005

48. Mishra S, Yadavan V (2013) Modeling and optimization of laser beam percussion drilling of thin aluminum sheet. Opt Laser Technol 48:461-474. https://doi.org/10.1016/j.optlastec.2012.10. 035

49. Casalino G, Losacco AM, Arnesano A, Facchini F, Pierangeli M, Bonserio C (2017) Statistical analysis and modelling of an Yb: KGW femtosecond laser micro-drilling process. Procedia CIRP 62:275-280. https://doi.org/10.1016/j.procir.2016.06.111

Publisher's note Springer Nature remains neutral with regard to jurisdictional claims in published maps and institutional affiliations. 